\title{
Por uma antropologia da comunicação: a construção de um campo e suas pesquisas ${ }^{1}$
}

\section{Isabel Travancas}

Universidade Federal do Rio de Janeiro

E-mail: isabeltravancas@yahoo.com 


\section{Resumo}

Este trabalho tem como objetivo discutir as relações e, principalmente, as contribuições da antropologia para o estudo e a pesquisa sobre os meios de comunicação. As ciências sociais em geral e a antropologia em particular só recentemente têm refletido de forma mais sistemática sobre os meios de comunicação de massa. Eles não foram, ao longo das últimas décadas, um tema privilegiado e assunto de dissertações e teses de doutorado nos Programas de Pós-Graduação em Antropologia Social no país. Em um breve levantamento em instituições acadêmicas dos grandes centros urbanos, nota-se que a mídia e, principalmente, a imprensa aparecem nas pesquisas como um elemento complementar. O foco deste trabalho é, portanto, a análise de algumas dessas teses e dissertações de antropologia, cujo tema central é a mídia. Através da leitura do conjunto de trabalhos, ficaram evidentes quatro eixos temáticos: a ideia de construção da notícia pela imprensa, utilizando a noção de representação; o discurso dos jornalistas sobre sua própria carreira e sobre os meios de comunicação de massa; as pesquisas sobre publicidade em geral e sobre publicitários; e os estudos sobre televisão e as etnografias de recepção que refletem sobre as interpretações e as ressignificações dos telespectadores dos programas da mídia televisiva.

Palavras-chave: antropologia; comunicação; mídia.
Abstract

The present work discusses the contributions of anthropology for the study and research on the mass media. Social sciences in general and anthropology in particular have been thinking systematically on the mass media in recent years. Over the last decades this has not been a primary theme of studies in master and phd thesis in the graduate programs in social anthropology in Brazil. In a brief research on academic institutions in the main cities, we noted that the media and specially the press appeared in researches as a complementary element. The focus of the present work is, therefore, to analyze some of those thesis. We managed to divide them according to four main thematic issues: newsmaking; the discourse of the journalists about their career and about the mass media; researche on advertising and advertisers; and studies on television and the ethnographies that reflected on television reception that reflect on the interpretations by television audiences.

Keywords: anthropology; communication; media. 


\section{Introdução}

$\mathrm{O}$ s meios de comunicação de massa e seus produtos são fundamentais para a compreensão dos fenômenos urbanos contemporâneos. Não é por acaso que muitos autores enfatizam que vivemos em uma sociedade midiática e estamos, portanto, imersos em um mar de informações de todos os tipos e provenientes dos mais diversos veículos. Ao lado disso, a indústria cultural - assim nomeada por Theodor Adorno e Max Horkheimer (1990) - encontra-se em plena transformação, com o surgimento de novos meios, como a TV a cabo, a internet e o DVD, além de novas linguagens. Nesse contexto parece-me importante e necessário refletir sobre como a antropologia tem contribuído para uma análise mais fecunda desse campo e quais as possibilidades futuras de articulação entre a antropologia e a comunicação.

A partir da leitura das pesquisas produzidas nos três Programas de Pós-Graduação em Antropologia (PPGAS) selecionados: Museu Nacional (UFRJ), Universidade de Brasília (UnB) e Universidade Federal do Rio Grande do Sul (UFRGS), já se pode ter uma ideia desse panorama. O Programa de Pós-Graduação em Antropologia Social do Museu Nacional foi o primeiro do país, tendo sido criado em 1968. Daquele momento até março de 2008 foram produzidas 187 teses e 364 dissertações. Do total de dissertações, cuja primeira é de 1970, 13 tratam dos meios de comunicação de massa, são elas: A ideologia dos publicitários, de Zilda Kacenik (1976); Magia e capitalismo: um estudo antropológico da publicidade, de Everardo Rocha (1982/ 1985); Mulher de novela e mulher de verdade: estudo sobre cidade pequena, mulher e telenovela, de Rosane Prado (1987); O belo sexo: imprensa e

\section{ILHA}

volume 10 - número 2 
identidade feminina no Rio de Janeiro em fins do século XIX e início do século XX, de Maria Fernanda Bicalho (1988); Novela e sociedade no Brasil, de Laura Graziela Gomes (1991); AIDS e a imprensa: um estudo de antropologia social, de Jane Galvão (1992); Telenovela e texto cultural: análise antropológica de um gênero em construção, de Monica Coutinho (1993); O jornal em pauta: um estudo sobre a coluna de cartas dos leitores do Jornal do Brasil, de Patrícia Burke (1996); A construção da notícia em dois jornais cariocas: uma abordagem etnográfica, de Silvia Nogueira (1998); A construção de um réu: payakãna na imprensa brasileira durante a ECO-92, de Maria José Alfaro Freire (2001); Do personagem à pessoa: socialidade cigana, comunicação de massa e mudança cultural, de Luís Eduardo Raulino (2003); e Mulher e diferença cultural em uma revista feminina popular, de Ana Teles da Silva (2004). Entre as teses, quatro tiveram como tema central a mídia: A sociedade do sonho: interpretação antropológica e indústria cultural, de Everardo Rocha (1989/1992); Repórteres, reportagem e construção da nação no jornalismo brasileiro, de Candice Vidal e Souza (2003); Facetas do rádio: uma etnografia das emissoras de Ilhéus (sul da Bahia), de Silvia Nogueira (2005); e Expansão do espaço jornalístico e transformações sociais em Buenos Aires, de Hernán Gomez (2005).

No Programa de Pós-Graduação da UFRGS, criado no início dos anos 1980, já foram elaboradas 174 dissertações e 35 teses até 2007. Entre as dissertações encontramos sete que abordam a mídia. A primeira é de Ondina Leal e se intitula A leitura social da novela das oito, de 1983. Essa pesquisa foi não só uma das primeiras sobre o tema, como se tornou uma referência nos estudos de recepção. Lúcia Müller é a autora de $A$ alma do negócio: um estudo antropológico sobre o uso da pesquisa de mercado na publicidade, de 1989; Míriam de Fátima Chagas escreveu Uma mão lava a outra: a interação de grupos populares com a rádio farroupilha, de 1993; e João Aníbal dos Santos é autor de Televisão: cultura local e cultura de massa global. Etnografia da audiência entre descendentes de imigrantes alemães no RGS, de 1995. É de Nara Magalhães o trabalho $A$ dimensão simbólica da política no cotidiano: uma análise da emissão da mensagem política e sua recepção por grupos populares de Porto Alegre, em alguns momentos eleitorais, de 1995. Se incluirmos os trabalhos sobre a internet dentro do universo das mídias, poderemos

ILHA

volume 10 - número 2 
Por uma antropologia da comunicação: a construção de um campo e suas pesquisas

pensar na dissertação de Jonatas Dornelles, intitulada Planeta Terra, cidade Porto Alegre: uma etnografia dos internautas, de 2003. A última dissertação abordando esse tema foi Sobre cinemas e vídeo-locadoras pornôs, provincias de outros corpos e outros significados, de Alexandre Luís Schultz Bier, de 2004. Em relação às teses, não foi encontrada nenhuma que tratasse dos meios de comunicação de massa.

O terceiro Programa de Pós-Graduação pesquisado foi o da UnB, criado no início dos anos 1970. De suas 237 dissertações defendidas a partir de 1974, apenas duas abordam a mídia, são elas: Uma antropologia na Terra de Marlboro ou a pragmática da ilusão na cultura de massa, de Letícia Vianna (1993); e As folhas do mal: espectros da antropologia da imprensa, de João Batista Torres (1994). Das 80 teses defendidas no Departamento, apenas uma trata da comunicação de massa: $O$ cinema brasiliense em uma narrativa antropológica, de Ariana Mota (2006).

Penso que hoje, mais do que nunca, é impossível refletirmos sobre as sociedades complexas urbanas contemporâneas sem darmos um lugar de destaque para os meios de comunicação de massa. Eles podem ser uma valiosa porta de entrada para compreendermos os fenômenos sociais produzidos por seus "nativos", assim como ajudam a desvendar seus "códigos" e "mapas". E precisam ser investigados na sua complexidade e riqueza para além de preconceitos e ideias preestabelecidas - muitas delas baseadas em uma leitura superficial da obra dos pensadores da Escola de Frankfurt - para deixarmos de encarar a indústria cultural como um mal em si, focando no significado das mensagens, na elaboração dos produtos e na interpretação de seus receptores.

Debra Spitulnik (1993, p. 293), em sua resenha sobre a interseção da antropologia com a comunicação, chama a atenção para o fato de ainda não ser possível falarmos em uma "antropologia dos meios de comunicação de massa", embora na última década tenha havido um aumento no interesse de estudá-los. Segundo Spitulnik (1993), há inúmeras maneiras de se abordarem antropologicamente os meios de comunicação de massa: como instituições, como lugares de trabalho, como práticas comunicativas, como produtos culturais, como atividades sociais, como formas estéticas e como desenvolvimentos históricos.

ILHA

volume 10 - número 2 
Isabel Travancas

Neste artigo, depois de ler a produção acadêmica dos antropólogos em alguns centros de pesquisa do país, escolhi privilegiar duas perspectivas: a de análise dos textos jornalísticos como produtos culturais, com características e objetivos específicos; e a de investigação do discurso dos jornalistas como produtores de uma linguagem, de um objeto de consumo e de uma lógica que se define a partir da prática profissional e que gera nos indivíduos desse grupo uma identidade social determinada.

\section{A construção da notícia}

Ainda que desde sempre tenha havido troca e circulação de informações, é no século XVIII, com a Revolução Industrial, que a imprensa se desenvolve e ganha força como um produto industrial com profissionais especializados. Atualmente, um grande jornal é uma empresa que produz milhares de exemplares, com estrutura organizacional supostamente bem planejada e administrada e com muitos funcionários em diferentes áreas de atuação. Mas o fundamental é que, na modernidade, o jornal se tornou um produto, uma mercadoria.

O “coração' de um jornal é a redação. É nela que são produzidas as notícias, mercadoria "vendida" pelo jornal e sua razão de ser. A redação se divide em editorias, que são setores do jornal. Um grande jornal tem cerca de dez editorias diferentes, que agrupam repórteres, redatores, diagramadores, editores, subeditores e chefes de reportagem. Essa divisão em editorias aponta para uma topografia do conhecimento em que os diferentes saberes são distribuídos em áreas estanques e distintas fisicamente. Essa separação, de certa forma, busca ser uma expressão da realidade, como se a realidade pudesse ser e fosse compartimentada em seções, ou seja, no "mundo do jornal" a vida será pautada, dividida e compreendida a partir dessas divisões em editorias e assuntos.

A dissertação de Silvia Nogueira (1998, p. 109) expressa seu interesse em investigar como se dá essa construção da notícia em dois jornais cariocas. Os jornais escolhidos foram renomeados, tor-

ILHA

volume 10 - número 2 
naram-se Correio da Cidade e Folha do Rio. A antropóloga acompanhou as atividades desenvolvidas nas redações, levando em conta os fatores ideológicos, mercadológicos e pessoais que atuavam na elaboração das matérias. Isso sem deixar de destacar as especificidades dessa prática profissional, com seus prazos restritos de tempo e suas regras de redação jornalística. Mesmo a pesquisadora tendo concluído que as preocupações fundamentais para os jornalistas são a concorrência e a relação com o tempo, isso não a impediu de perceber o quanto o "meio jornalístico é fortemente marcado por um dia-a-dia construído em bases de trocas. Trocas de gentilezas, de favores, de informações, de experiências, etc., onde aceitar trocar significa aceitar fazer parte de uma rede de relações própria ao meio jornalístico" (p. 109).

Creio que pensar em construção da notícia é pensar em representações. François Laplantine (2001, p. 241) afirma que, para a antropologia,

\begin{abstract}
a representação situa-se sempre: 1) na articulação do individual e do social; 2 ) em três campos de investigação: 0 do conhecimento - uma representação é um saber que não duvida de si mesmo; o do valor - uma representação não é apenas um saber que alguém a ele adere por considerá-lo inteiramente verdadeiro e bom: é uma avaliação; o da ação - uma representação não é redutível a seus aspectos cognitivos e avaliativos: simultaneamente expressiva e construtiva do social, consiste não somente num meio de conhecimento, mas em instrumento de ação.
\end{abstract}

A representação pode ser entendida como ponto de confluência do social com o individual, resultado de um saber que os integrantes de um grupo social constroem sobre sua vivência. E ela terá o papel de orientar a ação social porque é vivida como real. Indo nessa direção da construção de representações na imprensa, encontrei duas dissertações do PPGAS do Museu Nacional: A construção de um réu: payakã na imprensa brasileira durante a ECO-92, de Maria José Alfaro Freire (2001); e Mulher e diferença cultural em uma revista feminina popular, de Ana Teles da Silva (2004).

Maria José Alfaro Freire se propôs a estudar o tratamento dado pela imprensa brasileira à acusação de estupro dirigida ao índio kayapó

ILHA

volume 10 - número 2 
Paulinho Payakã em junho de 1992. Para isso, analisou as reportagens e os textos opinativos avaliando como são apresentados os fatos e em que medida são acionadas representações baseadas em consenso que, em última instância, questionam os direitos indígenas a partir de informações sobre os kayapós e as populações indígenas em geral. A autora percebeu um percurso do específico - o estupro para o geral - as questões indígenas. Os textos informativos chamavam a atenção para a violência do ato, para a prisão de Payakã e para os kayapó. Já nos artigos opinativos, segundo Freire, há uma “tendência dominante a tematizar, a partir da acusação das populações indígenas em geral, ou ainda, a relação destas com o Estado Brasileiro". (p. 127)

O trabalho sobre revistas femininas analisa seu conteúdo e a representação que seus produtores têm das leitoras. Ainda foram foco de atenção as cartas das leitoras, que ajudaram a pensar na interação do público com essa mídia específica. A pesquisadora percebeu que há uma distância entre o público leitor e o produtor da revista, uma vez que o primeiro é composto de segmentos populares da sociedade e o segundo, por segmentos letrados de camadas médias. A seu ver, isso explica o tom didático presente em várias seções e em reportagens explicativas. Em alguns casos, trazem notícias veiculadas em outros orgãos da imprensa que nas revistas aparecem resumidas e explicadas. Está sempre presente a ideia de orientação para a leitora.

Esse caráter pedagógico destacado por Silva (2004) não surge apenas nos textos jornalísticos. Ele foi notado na fala dos produtores. A seu ver, isso demonstra "uma intenção de tornar inteligíveis e alcançáveis para a leitora as instituições governamentais, os sistemas econômicos, jurídico, de ensino, entre outros e as notícias veiculadas na mídia em geral" (p. 90). A ideia de representação é facilmente identificada nos discursos escrito e falado.

O jornalismo produz discursos em condições particulares, que não são nem cultural nem socialmente neutras, ainda que nem sempre os jornalistas enfatizem esse aspecto. Para o jornalismo, a objetividade junto com a clareza e a concisão são regras imprescindíveis

ILHA

volume 10 - número 2 
da notícia. Por mais que os manuais de redação afirmem que a objetividade perdeu seu peso, ela não foi descartada e continua a ser uma meta. É o caso do Manual da Redação da Folha de S. Paulo (2001, p. 28), que afirma:

Não existe objetividade em jornalismo. Ao escolher um assunto, redigir um texto e editá-lo, o jornalista toma decisões em larga medida subjetivas, influenciadas por suas posições pessoais, hábitos e emoções. Isso não o exime, porém, da obrigação de ser o mais objetivo possível. Para relatar um fato com fidelidade, reproduzir a forma, as circunstâncias e as repercussões, o jornalista precisa encarar o fato com distanciamento e frieza, o que não significa apatia nem desinteresse.

Com a transformação dos jornais em empresas cujo principal produto é a notícia, houve uma tentativa de padronizar os textos produzidos dentro das redações. O lide criado pela imprensa norteamericana teve como objetivo atender ao leitor moderno e apressado que precisa obter o maior número de informações no menor tempo possível. É exigido do jornalista que ele seja capaz de criar e inovar a partir dessa fórmula, respondendo com eficiência às perguntas fundamentais sobre o fato noticiado.

As folhas do mal? Espectros da antropologia na imprensa é o título da dissertação de João Batista de Miranda Torres, defendida na UnB em 1994. O objetivo de sua pesquisa foi analisar a construção da notícia a partir de sua experiência etnográfica como repórter do caderno SP-Nordeste, de Ribeirão Preto, editado pelo jornal Folha de S. Paulo. Torres (1994, p. 299) redigiu um trabalho pouco convencional abordando do niilismo ao relativismo, passando pelo barroco para discutir as narrativas jornalísticas. Ao mesmo tempo que descreve rotinas e práticas como a pauta e o fechamento da edição, faz uma crítica contundente à imprensa:

O jornal não interpreta a linguagem dessa maneira. Prefere vê-la como legítima representação da verdade. Para isso, aperfeiçoa toda técnica de controle lingüístico, de sorte que a descrição do fato não forneça a impressão de ocupar o lugar do fato, mas sim que seja o próprio fato.

ILHA

volume 10 - número 2 
Isabel Travancas

Para o pesquisador, o jornal não se pensa como uma construção da realidade. Entretanto, o trabalho dos antropólogos tem sido chamar a atenção para essa perspectiva de que a imprensa funciona como um "mapa" do mundo para seus leitores. E, como tal, deve estar sintonizado com os interesses, os objetivos e as perspectivas do seu público.

Nesse sentido, o trabalho de Patrícia Burke (1996) - O jornal em pauta: um estudo sobre a coluna de cartas dos leitores do Jornal do Brasil pode contribuir para uma reflexão sobre esse público leitor e sua visão dos jornais, uma vez que, para muitos jornalistas, o leitor é uma incógnita, apesar das inúmeras pesquisas de mercado. Robert Darnton (1990, p. 83) comenta que os jornalistas do New York Times (NYT) acreditavam que os editores esperavam que eles escrevessem para uma garota de 12 anos de idade. Alguns se perguntavam se essa "criatura imaginária" constava do manual de redação do jornal.

Burke (1996) afirma que a coluna Opinião dos Leitores funciona como parâmetro para a observação das tendências da opinião pública em relação a temas relevantes. Ela destaca que no debate público o que se estabelece é prioritariamente a pauta do jornal, que funciona como definidora dos temas a serem discutidos. Além disso, a coluna é vista como um lugar inserido no jornal e a intervenção nela representa um meio de falar com e através dele. Esse seria o espaço de possibilidade de o leitor interferir na construção da realidade através de um veículo de informação. A antropóloga (1996, p. 127) concluiu que "de certa forma, na coluna de cartas dos leitores, para além da pauta do jornal, o que está de fato em pauta é o próprio jornal e o poder a ele atribuído como referencial de mobilização dentro de uma comunidade de interesses".

\section{O discurso dos jornalistas}

Destacarei aqui alguns trabalhos que problematizam essa categoria profissional, realizando etnografias, ouvindo seus depoimentos, discutindo não só sua relação com a imprensa mas também com a profissão e com seus leitores e/ou ouvintes. Discutirei minha pró- 
pria pesquisa $O$ mundo dos jornalistas (1993), Repórteres, reportagem e construção da nação no jornalismo brasileiro, de Candice Vidal e Souza (2003), e Facetas do rádio, de Silvia Nogueira (2005).

O jornalista é, antes de tudo, um habitante da cidade. O mundo urbano tem características e particularidades que se expressam no jornalismo. Quando Georg Simmel (1979) cita o anonimato, as relações transitórias e a superficialidade como aspectos dos indivíduos urbanos, não se pode deixar de associar essas características ao jornalista. O jornalista experimentará no seu cotidiano a cidade como espaço da diversidade, do cruzamento de mundos e "tribos" diferentes, desvendando territórios heterogêneos e construindo, assim, um mapa, para muitos habitantes, desconhecido. Ao estudar um grupo de 50 jornalistas da grande imprensa do Rio de Janeiro e de São Paulo (Travancas, 1993, p. 102), pude constatar que se por um lado a profissão de jornalista sintetiza as características do indivíduo, resultando em uma totalização do jornalista sob o prisma de sua identidade, por outro percebi que há uma tensão entre esse papel totalizante e outros papéis ligados, como, por exemplo, às relações de parentesco e de família. Acredito que é possível falar de uma identidade de jornalista que se constrói apesar ou sobre essa tensão, ou seja, essa identidade não é exclusivista ou determinante, ela é síntese de uma série de papéis desempenhados por um indivíduo, com funções diversas.

As noções de prestígio e ascensão social, bastante relacionadas entre si, também ajudaram a compor o quadro da construção da identidade do jornalista. Pelas entrevistas, ficou claro que a carreira de jornalista poderá significar, em alguns casos, um instrumento de ascensão social e obtenção de prestígio. Obviamente, os dois aspectos terão dimensões variadas de acordo com cada indivíduo. Para um jornalista oriundo de uma classe alta, com um sobrenome de prestígio social e sem dificuldades financeiras, a carreira não será uma chance de conquista de status, porque ele já o tinha anteriormente. Ela poderá, no entanto, legitimá-lo ou reforçá-lo. Entretanto, para um indivíduo em outras condições, ela será um importante instrumento para ascensão na sociedade. O que quero deixar claro é que essa chance de

ILHA

volume 10 - número 2 
mudança social, ainda que escassa em termos quantitativos, é um fator de motivação e influência na escolha da profissão, mesmo que não apareça explicitamente nos discursos dos entrevistados.

Ficou claro para mim que determinadas carreiras significam bem mais do que uma atividade ou emprego na vida de seus profissionais, gerando um envolvimento que resultará num estilo de vida e numa visão de mundo específicos. Compreendo que a visão de mundo e o estilo de vida desses jornalistas são o resultado de seu envolvimento com a profissão ou, como nos termos de Howard Becker (1977), de uma adesão. Essa adesão significa um envolvimento, mas de outra esfera. Trata-se de um movimento abrangente da carreira em relação aos outros setores da vida do indivíduo, determinando, como o próprio termo demonstra, uma adesão à profissão. A carreira é vista, então, como expressão de suas individualidades, da mesmo forma que seus selves se percebem expressos por ela, em uma relação de complementaridade.

A tese de Candice Vidal e Souza (2003) tem como objetivo principal a constituição da reportagem como gênero narrativo. Ela é produto da observação direta do repórter que narra o que vê em suas viagens pelo Brasil, sempre dentro de um estilo jornalístico. Entretanto, ao buscar entender como se dá a construção da nação brasileira no discurso da imprensa - em particular a Folha de S. Paulo, de 1974 a 1994 - , Souza (2003) se detém obrigatoriamente nos seus mentores: os repórteres. A meu ver, o repórter é a figura paradigmática do jornalismo. Pelas tarefas diárias, que vão desde a apuração dos fatos até a redação da notícia, ele pode ser visto como um profissional que atravessa fronteiras e tem acesso livre a quase todos os lugares, dos meios oficiais aos marginais e perigosos - um cidadão do mundo. Ao entrar em contato com diferentes realidades, realiza o papel de mediador entre o leitor e o mundo.

Robert Darnton (1990), em seu artigo Jornalismo: toda notícia que couber, a gente publica, fala de sua breve experiência como repórter em The New York Times e analisa a construção da notícia, as especificidades do trabalho dos jornalistas e o papel do correspondente do jornal. Darnton salienta que o NYT a cada três anos transfere os seus correspondentes de local. O jornal acredita que haja uma 
tendência de seus correspondentes estrangeiros desenvolverem uma visão favorável ao país onde moram. Há uma preocupação importante por trás dessa estratégia. Souza (2003) chama a atenção para outras particularidades, no caso, dos correspondentes masculinos. Segundo ela, "eles parecem pensar como o militar egípcio" (p. 89), excluindo as mulheres, acusando-as de aproveitar seu tempo para tomar sol nos hotéis ou se aproximarem de um colega para obter proteção durante a guerra, por exemplo. Ela salienta que "a communitas jornalística no estrangeiro é composta por homens" (p. 89).

O Prêmio Esso é outro assunto abordado na tese de doutorado de Souza (2003, p. 270). Ele é visto como um dos processos de legitimação e consagração da reportagem e do repórter dentro do campo jornalístico brasileiro. Muitos aspectos são importantes, como as fronteiras que delimitam a identidade profissional assim como sua qualidade. Há toda uma hierarquização da carreira, do universo das empresas de comunicação e da própria geografia do país. E o discurso dos ganhadores, como chama a atenção a pesquisadora, enfatiza a excelência jornalística definida através desse ritual de avaliação realizado por membros da própria comunidade. Ela conclui afirmando que "os percursos de consagração internos ao campo jornalístico só fazem reforçar e estimular as naturalizações".

Analisar cinco emissoras de rádio de Ilhéus, Bahia, foi o objetivo central da tese de doutorado de Silvia Nogueira (2005, p. 141). A antropóloga realizou uma detalhada etnografia dos veículos, destacando as relações que se estabelecem nesse campo específico. Discutiu o exercício profissional do radialista e suas vivências e a importância da profissão em suas vidas. Seus entrevistados apresentaram distinções, como ser radialista de AM e FM, que apontam para a noção de prestígio. Um ponto importante e de contato com minha própria pesquisa (Travancas, 1993) é o fato de a profissão ser percebida "como algo que traz mais felicidades do que infelicidades" (p. 143) para muitos, assim como pode "ser sentida como um vício, um carma ou um grande amor" (p. 141) e, por fim, a impossibilidade de abandonarem a profissão.

Outros aspectos apareceram no discurso dos nativos, como a distinção entre locutor e comunicador. Locutor é uma função infe-

ILHA

volume 10 - número 2 
rior, de acordo com esses radialistas, e exige menos habilidades de seu profissional do que a de comunicador. O comunicador coloca sentimento, comove, improvisa, interpreta, enquanto ao locutor basta ler ou falar uma informação.

Ao lado disso, há a questão do estilo de vida também presente. Os radialistas da pesquisa de Silvia Nogueira (2005, p. 139) afirmam que os profissionais de FM têm "um jeito descontraído de viver. O compromisso é com a diversão, com o alto astral", enquanto que os de AM teriam um estilo de "emoção ao falar, sensibilidade aos problemas do povo e compromisso em informar o povo sobre o que está acontecendo".

Três pesquisas muito distintas e também muito próximas. Elas demonstraram como penetrar na vastidão do campo da comunicação de massa através de seus produtores pode ser esclarecedor não apenas da identidade desses profissionais como do próprio campo jornalístico no qual estão inseridos.

\section{Considerações finais}

A indústria cultural tem sido muito criticada em inúmeros trabalhos acadêmicos, e ainda são escassas as investigações sobre seus emissores, seus receptores e suas mensagens produzidas dentro do campo da antropologia. Este artigo procurou fazer um pequeno levantamento dos trabalhos elaborados nessa área no país.

Creio que, como salientou Spitulnik (1993) em relação ao universo antropológico inglês e norte-americano, também no Brasil a maioria dos estudos sobre a mídia tem centrado a sua atenção nos textos, sejam eles jornalísticos, publicitários ou de outras áreas. Entretanto, isso começa a se transformar e há algumas pesquisas que buscam incorporar a metodologia antropológica para pensar a mídia e seus receptores. Não que a análise dos textos deva ser desprezada, pelo contrário, mas ela não é a única possibilidade para esboçar um retrato mais profundo da mídia. Nesse sentido, muitas vezes percebe-se o quanto falta aos antropólogos dominar as particularidades desse campo de representações coletivas.

ILHA

volume 10 - número 2 
Ao refletir sobre a imprensa, um dos eixos temáticos privilegiados neste artigo, achei importante destacar que os textos e as reportagens analisados nos trabalhos aos quais me referi devem ser entendidos não como um mero locus de observação de representações no qual as vozes dessas sociedades se fazem presentes, mas sim como mais um agente produtor dessas representações, ou seja, se chamei a atenção para o fato de o jornalista ser um mediador entre a informação e o indivíduo, não foi para destacar a imprensa apenas como uma mediadora de distintas vozes. Ela própria é uma voz ativa, e isso ficou claro em vários trabalhos.

Ainda em relação à construção do jornalismo, vale lembrar que ele está preocupado em se distanciar da subjetividade. O texto jornalístico não pode conter a opinião do repórter ou as suas impressões pessoais. Ele está ali para "relatar os fatos", ouvir as fontes, os envolvidos, de preferência dos dois ou mais lados da questão. Da mesma maneira, ele não deve escrever um relato dos acontecimentos que o envolva, salvo em raras exceções. O jornalista deve ser testemunha e a mais objetiva possível. Há uma ideia de "perigo" associada à subjetividade no jornalismo. Há uma busca de "pureza" que me faz lembrar a obra Pureza e perigo, de Mary Douglas (1976). Nesse livro a antropóloga discute a questão da poluição e da sujeira em inúmeras culturas e em diferentes aspectos, como a alimentação, a religião, os rituais, entre outros. Em relação à discussão deste artigo, percebo duas possibilidades de reflexão em relação a essa "poluição". Os textos jornalísticos, de um modo geral, fogem da subjetividade, que pode ser encarada como um perigo, como um agente poluidor da notícia e ameaçador da sua objetividade. O outro aspecto diz respeito ao próprio campo das relações entre a antropologia e a comunicação, ainda em constituição no universo acadêmico brasileiro. Não é à toa que Sara Dickey (1997) afirma que, se os antropólogos não disseram grande coisa sobre a importância social e cultural dos meios de comunicação, muitos outros disseram, principalmente dentro da área dos chamados estudos culturais. A seu ver, os meios de comunicação são uma categoria importante de experimentação e estudo.

ILHA

volume 10 - número 2 
O segundo eixo temático - o discurso dos jornalistas sobre sua própria carreira e sobre os meios de comunicação de massa -, ainda que tenha um número mais reduzido de trabalhos, demonstrou o quanto os jornalistas têm uma relação particular com sua profissão, como se relacionam dentro desse universo competitivo, quais as regras para o exercício profissional, além de explicitar as relações de poder que constituem e definem esse campo. Ficou claro o quanto o jornalista realiza o papel de mediador entre o leitor e o mundo, entrando em contato com diferentes realidades a cada dia. Como afirmei ao longo do trabalho, acredito que o repórter seja a figura paradigmática do jornalismo. E esse lugar tão central na carreira também está relacionado com a sua função social. Ele tem um papel importante em termos de construção da cidadania, uma vez que é responsável pela transmissão de informações; e a ideia de cidadania está subordinada à informação. Não há cidadão sem conhecimento, é esse conhecimento que torna o indivíduo um cidadão, na medida em que as informações lhe possibilitam escolhas, avaliações e participação na sociedade. E é também para esse aspecto que as três pesquisas se voltam.

Procurei fazer aqui um primeiro e breve levantamento da produção acadêmica de alguns Programas de Pós-Graduação em Antropologia no país. Sem dúvida, vários trabalhos e universidades importantes ficaram de fora. Este é um trabalho inicial que pretendo prosseguir para abordar os outros dois eixos temáticos que apontei anteriormente: o discurso da publicidade e dos publicitários e os estudos sobre televisão e sua recepção. Creio que esse seja o caminho para estreitar os laços entre estes dois campos - antropologia e comunicação - e estabelecer um fértil diálogo entre eles.

\section{Referências}

ADORNO, Theodor; HORKHEIMER, Max. Dialética do esclarecimento. Rio de Janeiro: Zahar, 1990.

ALMEIDA, Heloisa Buarque de. Telenovela, consumo e gênero. Bauru, SP: EDUSC, 2003.

ILHA

volume 10 - número 2 
Por uma antropologia da comunicação: a construção de um campo e suas pesquisas

BECKER, Howard. Sociological Work, Method and Substance. News Brunswick: Transaction Books, 1977.

BICALHO, Maria Fernanda. 1988. O belo sexo: imprensa e identidade feminina no Rio de Janeiro em fins do século XIX e início do século XX. Dissertação (Mestrado em Antropologia Social) - Programa de Pós-Graduação em Antropologia Social, Universidade Federal do Rio de Janeiro, 1988. Mimeografado. 269f.

BIER, Alexandre Luís Schultz. 2004. Sobre cinemas e vídeo-locadoras pornôs, províncias de outros corpos e outros significados. Dissertação (Mestrado em Antropologia Social) - Programa de Pós-Graduação em Antropologia Social, Universidade Federal do Rio Grande do Sul, 2004.

BURKE, Patrícia. 1996. O jornal em pauta: um estudo sobre a coluna de cartas dos leitores do Jornal do Brasil. Dissertação (Mestrado em Antropologia Social) - Programa de Pós-Graduação em Antropologia Social, Universidade Federal do Rio de Janeiro, Rio de Janeiro, 1996. Mimeografado. 131f.

CHAGAS, Míriam de Fátima. 1993. Uma mão lava a outra: a interação de grupos populares com a rádio farroupilha. Dissertação (Mestrado em Antropologia Social) - Programa de Pós-Graduação em Antropologia Social, Universidade Federal do Rio Grande do Sul, 1993. Mimeografado.

COUTINHO, Monica R. 1993. Telenovela e texto cultural: análise antropológica de um gênero em construção. Dissertação (Mestrado em Antropologia Social) - Programa de Pós-Graduação em Antropologia Social, Universidade Federal do Rio de Janeiro, 1993. Mimeografado. $239 f$.

DARNTON, Robert. O beijo de Lamourette. São Paulo: Cia das Letras, 1990.

DICKEY, Sara. La antropologia y sus contribuciones al estudio de los medios de comunicación. Revista Internacional de Ciências Sociais, UNESCO, n. 153, p. 1-23, 1997. Disponível em: <www.unesco.org/issj/rics 153/dickeyspa.html>. Acesso em: 10 mar. 2000.

DORNELLES, Jonatas. 2003. Planeta Terra, cidade Porto Alegre: uma etnografia dos internautas. Dissertação (Mestrado em Antropologia Social) - Programa de Pós-Graduação em Antropologia Social, Universidade Federal do Rio Grande do Sul, 2003. Mimeografado.

DOUGLAS, Mary. Pureza e perigo. São Paulo: Perspectiva, 1976.

DURKHEIM, Émile; MAUSS, Marcel. Contribuição para o estudo das representações coletivas. In: MAUSS, Marcel. Ensaios de sociologia. São Paulo: Perspectiva, 1981. p. 399-455.

FOLHA DE S. PAULO. Manual da Redação. São Paulo: Folha de S. Paulo, 2001.

ILHA

volume 10 - número 2 
FREIRE, Maria José Alfaro. 2001. A construção de um réu: payakã na imprensa brasileira durante a ECO-92.Dissertação (Mestrado em Antropologia Social) - Programa de Pós-Graduação em Antropologia Social, Universidade Federal do Rio de Janeiro, 2001. Mimeografado. 154f.

GALVÃO, Jane L. F. L. 1992. AIDS e a imprensa: um estudo de antropologia social. Dissertação (Mestrado em Antropologia Social) - Programa de PósGraduação em Antropologia Social, Universidade Federal do Rio de Janeiro, 1992. Mimeografado. 151f.

GOMES, Laura Graziela F. F. 1991. Novela e socidade no Brasil. Dissertação (Mestrado em Antropologia Social) - Programa de Pós-Graduação em Antropologia Social, Universidade Federal do Rio de Janeiro, 1991. 179f.

GOMEZ, Hernán Eufemio. 1999. Uma análise etnográfica do espaço das escolas de jornalismo de Buenos Aires. Dissertação (Mestrado em Antropologia Social) Programa de Pós-Graduação em Antropologia Social, Universidade Federal do Rio de Janeiro, 1999. Mimeografado. $114 \mathrm{f}$.

KACENILK, Zilda. 1976. A ideologia dos publicitários. Dissertação (Mestrado em Antropologia Social) - Programa de Pós-Graduação em Antropologia Social, Universidade Federal do Rio de Janeiro, 1976. Mimeografado. 80f.

LAPLANTINE, François. Antropologia dos sistemas de representações da doença: sobre algumas pesquisas desenvolvidas na França contemporânea reexaminadas à luz de uma experiência brasileira. In: JODELET, Denise (Org. ). As representações sociais. Rio de Janeiro: Ed. UERJ, 2001. p. 241-259.

LEAL, Ondina F. A leitura social da novela das oito. Petrópolis: Vozes, 1986.

MAGALHÃES, Nara M. E. 1995. A dimensão simbólica da política no cotidiano: uma análise da emissão da mensagem política e sua recepção por grupos populares de Porto Alegre, em alguns momentos eleitorais. Dissertação (Mestrado em Antropologia Social) - Programa de Pós-Graduação em Antropologia Social, Universidade Federal do Rio Grande do Sul, 1995. Mimeografado.

MORGADO, Paula. Os Wayana através das emissões televisivas francesas 1961 2001: fatos e ficções, imagens e representações. In: XXV ENCONTRO ANUAL DA ANPOCS, 2001, Caxambu. Seminário temático: Os usos da imagem nas ciências sociais. Mimeografado.

MOTA, Ariana T. 2006. O cinema brasiliense em uma narrativa antropológica. Tese (Doutorado em Antropologia) - Departamento de Antropologia, Universidade de Brasília, 2006. Mimeografado.

MÜLLER, Lúcia H. A. 1989. A alma do negócio: um estudo antropológico sobre o uso da pesquisa de mercado na publicidade. Dissertação (Mestrado em Antropologia Social) - Programa de Pós-Graduação em Antropologia Social, Universidade Federal do Rio Grande do Sul, 1989. Mimeografado.

\section{ILHA}


Por uma antropologia da comunicação: a construção de um campo e suas pesquisas

NOGUEIRA, Silvia Garcia. 1998. A construção da notícia em dois jornais cariocas: uma abordagem etnográfica. Dissertação (Mestrado em Antropologia Social) - Programa de Pós-Graduação em Antropologia Social, Universidade Federal do Rio de Janeiro, 1998. Mimeografado. 126f.

2005. Facetas do rádio: uma etnografia das emissoras de Ilhéus ( sul da Bahia). Tese (Doutorado em Antropologia Social) - Programa de PósGraduação em Antropologia Social, Universidade Federal do Rio de Janeiro, 2005. Mimeografado. 388f.

PRADO, Rosane. 1987. Mulher de novela e mulher de verdade: estudo sobre cidade pequena, mulher e telenovela. Dissertação (Mestrado em Antropologia Social) - Programa de Pós-Graduação em Antropologia Social, Universidade Federal do Rio de Janeiro, 1987. Mimeografado. 258f.

. Televisão, poderosa mas não tanto: cidade pequena, mulher e televisão. In: ECKERT, Cornélia; MONTE-MÓR, Patrícia (Org.). Imagem em foco. Porto Alegre: Ed. UFRGS, 1999.

RAULINO, Luís Eduardo G. 2003. Do personagem à pessoa: socialidade cigana, comunicação de massa e mudança cultural. Dissertação (Mestrado em Antropologia Social) - Programa de Pós-Graduação em Antropologia Social, Universidade Federal do Rio de Janeiro, 2003. Mimeografado. 140f.

ROCHA, Everardo. Magia e capitalismo. São Paulo: Brasiliense, 1989.

. A sociedade do sonho: interpretação antropológica e indústria cultural. Rio de Janeiro: Mauad, 1995.

SANTOS, João Aníbal dos. 1995. Televisão: cultura local e cultura de massa global. Etnografia da audiência entre descendentes de imigrantes alemães no RGS. Dissertação (Mestrado em Antropologia Social) - Programa de PósGraduação em Antropologia Social, Universidade Federal do Rio Grande do Sul, 1995.

SILVA, Ana Teles da. 2004. Mulher e diferença cultural em uma revista feminina popular. Dissertação (Mestrado em Antropologia Social) - Programa de PósGraduação em Antropologia Social, Universidade Federal do Rio de Janeiro, 2004. $98 f$.

SIMMEL, Georg. A metrópole e a vida mental. In: VELHO, Otávio. (Org. ). 0 fenômeno urbano. Rio de Janeiro: Zahar, 1979. p. 11-25.

SOUZA, Candice Vidal e. 2003. Repórteres, reportagem e construção da nação no jornalismo brasileiro. Tese (Doutorado em Antropologia Social) - Programa de Pós-Graduação em Antropologia Social, Universidade Federal do Rio de Janeiro, 2003. Mimeografado. 325f.

SPITULNIK, Debra. Anthropology and Mass Media. Annual Review of Anthropology, v. 22, p. 293-314, 1993.

ILHA

volume 10 - número 2 
Isabel Travancas

TORRES, João Batista de Miranda. 1994. As folhas do mal? Espectros da antropologia na imprensa. Dissertação (Mestrado em Antropologia Social) Programa de Pós-Graduação em Antropologia Social, Departamento de Antropologia, Universidade de Brasília, Brasília, 1994. Mimeografado.

TRAVANCAS, Isabel. O mundo dos jornalistas. São Paulo: Summus Editorial, 1993.

VIANNA, Letícia. 1993. Uma antropologia na Terra de Marlboro ou a pragmática da ilusão na cultura de massa. Dissertação (Mestrado em Antropologia Social) Programa de Pós-Graduação em Antropologia Social, Departamento de Antropologia, Universidade de Brasília, Brasília, 1993. Mimeografado.

\section{Nota:}

1 Uma primeira versão deste texto foi apresentada na $26^{a}$ Reunião Brasileira de Antropologia, realizada entre os dias 01 e 04 de junho de 2008, em Porto Seguro, Bahia, Brasil.

Recebido em: 19/07/2008

Aceite em: 09/08/2008 